

\title{
Experiencia y propuesta didáctica para abordar la práctica decolonial desde las artes visuales contemporáneas
}

\section{Experience and teaching approach for dealing with de-colonial practice in contemporary visual aesthetics}

\section{Nuria Rey Somoza}

ISSN (imp): 1390-4825

ISSN (e): 2477-9199

\author{
Fecha de recepción: 15/10/17 \\ Fecha de aceptación: 5/10/18
}

\section{Resumen:}

Las posiciones dentro del pensamiento decolonial fortalecen la idea de igualdad entre sociedades desde la importancia de respetar las diferencias y equilibrar su valor histórico. Incluir estos planteamientos en el contexto educativo permite construir nuevos imaginarios sociales a nivel colectivo que replanteen su propia cultura desde una perspectiva crítica. En el texto se expone cómo la estética puede ser un elemento determinante en este giro decolonial para la búsqueda de identidad social en el contexto universitario ecuatoriano. El artículo contempla la propuesta didáctica implementada bajo este tema, así como las conclusiones que se extraen de esta experiencia.

\section{Pallabras clave:}

Educación artística, estética decolonial, pedagogía crítica, universidad

\section{Abstract:}

The views within colonial thoughts reinforce the idea of equality between societies because of the importance of respecting differences and balance their historical value. The fact of including these proposals in the educational contexts builds new social contexts to rethink their culture from a critical perspective. The text shows how aesthetics can be a defining factor in the colonial turn, to search a social identity in the Ecuadorian university context. This paper also exposes didactic proposals implemented for this theme, as well as the conclusions of this experience.

\section{Key Words:}

Art education, decolonial aesthetic, critical pedagogy, university

\section{Biografía de la autora:}

Nuria Rey Somoza. Madrid, 1991. Graduada en Bellas Artes y Máster en Educación Artística en Instituciones Sociales y Culturales, Universidad Complutense de Madrid. Desarrolla su Doctorado desde el año 2016 (UCM, España). Trabaja como docente-investigadora en la Escuela de Diseño Gráfico de la PUCE Sede Esmeraldas, es la responsable de investigación de la escuela. Ha colaborado en diferentes proyectos artístico-educativos desde la mediación en entornos sociales y culturales. 


\section{INTRODUCCIÓN}

Diversos planteamientos giran en torno a la decolonialidad, que se corresponden con el cuestionamiento de la modernidad colonial (De Oto, s.f.). Albán (2009), remitiéndose a teóricos como Jameson (1995) o Zizek (1998), expone la decolonialidad como el proceso de reconocimiento de historias y formas de ser alejadas de los parámetros supuestos del proyecto hegemónico. Los estudios decoloniales han fomentado propuestas transversales entre distintas áreas socioculturales, que serán las que conformen a nivel práctico cómo se vive esa decolonización (Medrazza, 2008). Desde las artes, esta transversalidad se entiende como "estética decolonial", agrupando una serie de manifestaciones artístico-culturales próximas a los planteamientos de esta corriente. En Ecuador, existen artistas cuyos trabajos dialogan entre las estéticas de herencia prehispánica y las coloniales. Estos planteamientos perduran en la exhibición de proyectos en espacios de carácter oficial, como "No Lugar" o el Centro de Arte Contemporáneo (Quito), así como en otros circuitos informales de debate y creación. Uno de los documentos que legitima las prácticas de este tipo es el Plan Nacional del Buen Vivir (2013). Este plan, de modo similar a otros implementados para las políticas socioculturales y económicas de algunas democracias latinoamericanas, se fundamenta en el término "buen vivir" en la medida en que da cabida a la heterogeneidad de prácticas e identidades sociales, y se ofrece como alternativa a la colonialidad global (Quijano, 2012). Sin embargo, este enfoque ha sido criticado por venir de un pasado folclórico y, al mismo tiempo, abandonar los saberes ancestrales a favor de una perspectiva globalizada (Gudynas, 2013).

Este texto expone la experiencia de llevar el debate decolonial al contexto universitario desde las estéticas y la cultura visual para explorar la construcción y deconstrucción de identidad.

\section{GIRO Y ESTÉTICA DECONONIAL}

Aunque no es el propósito de este trabajo realizar una reflexión de los debates sobre la decolonialidad, se entiende que es necesario, al menos, exponer los pilares del giro decolonial y sus expresiones en otros círculos. En esencia, la decolonialidad consiste en contestar o buscar una ruptura con el discurso modernidad/colonialidad, configurando un entramado de lógicas y prácticas de diferente identidad según el contexto determinado. En este sentido, Quijano (2002) entiende que la corriente decolonial debe enfrentarse a cuatro ejes de la sociedad e historia hegemónica: 1) la colonialidad del poder (idea de "raza" para la configuración social), 2) el capitalismo, 3) la idea de Estado/Nación como mecanismo de control, y 4) el eurocentrismo (en su concepción de dominio de subjetividades). En el mismo sentido, Walsh (2008) explica la colonial en función de la colonialidad del poder, la del saber, la del ser y la de apropiación de la naturaleza y la vida. Complementan y discuten estos aspectos otros estudiosos como De Sousa Santos (2010) o, Escobar (2010), entre otros.

El fenómeno de turn o "giro", según los razonamientos de Rogoff (2011, p.261), se produce cuando "nos movemos hacia o alrededor de algo (...). Cuando nos movemos, algo se activa dentro de nosotros, quizás incluso se actualiza”. Del giro decolonial deriva una red de estrategias que permiten cuestionar la manera en que se interiorizan estos planteamientos, una de ellas es la estética decolonial, que se preocupa por llevar al imaginario colectivo estos principios a través de las artes. Según Campos (2013), este ámbito permite desarrollar la acción desde una posición de desobediencia desde el plano estético. De esta manera, nace toda una gama de imágenes que reflejan la heterogeneidad de las culturas, como afirma León (2012, p.110): "los estudios visuales (...) tienen como desafío pendiente la construcción de un lugar de enunciación donde sus saberes se sitúen histórica y geopolíticamente." Más en profundidad, Albán (2013) relaciona el giro decolonial con las artes entendiendo que estas, además de los productos que genera, suponen el desarrollo de procesos sociales, en los cuales los creadores replantean las realidades del entorno, cuestionando elementos como lo apropiado, lo propio o lo bello. De esta manera, plantean nuevas maneras de afrontar la existencia con discursos simbólicos que enfrenten las desigualdades.

Uno de los proyectos que legitimó esta corriente de conocimiento fue Estéticas decoloniales (Gómez y Mignolo, 2012). El evento consistió en una exhibición con trabajos de artistas como Benjamín Jacanamijoy, Nadín Ospina o Tanja Ostojic, y un debate acerca de diversos abordajes teóricos. El discurso curatorial sobre el que se construyó 
consistió en entender los trabajos artísticos como elementos capaces de producir transformaciones significativas frente a procesos globalizadores (Rubiano, 2012). En este evento se determinaron algunas características de las estéticas decoloniales: la reivindicación histórica, el esfuerzo por legitimar identidades culturales desde lo colectivo y lo particular, y el concepto de frontera (Rubiano, 2012).

\section{MÉTODO Y APUNTES PREVIOS}

El contexto de implementación del proyecto mencionado se sitúa en la Pontificia Universidad Católica de Ecuador Sede Esmeraldas, durante el curso 2015-16, desde la materia de Teoría e Historia del Diseño, de la carrera de Diseño Gráfico, con un grupo de 11 estudiantes. A través de un cuestionario que sirvió como aproximación al tema en el contexto, se determinó que: la mayoría nunca recibió información sobre decolonialidad en estudios previos al universitario (aunque alguno lo conocía desde el ámbito informal) y todos reconocieron interés en abordarlo desde las artes visuales a partir de materiales actuales y familiares a ellos (videos, creaciones artísticas populares, música, recursos del humor, etc.).

La propuesta que se presenta tiene como objetivo acercar los planteamientos de la corriente decolonial a través de las artes visuales contemporáneas como estrategias para el proceso de aprendizaje, de la manera en que lo entiende Albán (2009, p.89) cuando defiende una pedagogía que aborde las "genealogías y trayectorias creativas diferentes a los presupuestos del arte occidental, sin que esto implique que en la actualidad no estén permeadas e involucradas en los circuitos de producción, distribución y consumo". Incluir estos planteamientos implica que la acción educativa favorezca la práctica deconstructiva (Albán, 2007), así como apostar por un entorno que favorece el pensamiento crítico y el interés del alumnado (Acaso, 2013). Además, Albán (2013) defiende unas prácticas artístico-culturales situadas o "basadas en lugar" como posibilidad de reapropiación y re-existencia, contextualizando los procesos para el debate simbólico identitario.

\section{ESTÉTICA DECOLONIAL EN LA UNI- VERSIDAD: PROPUESTA EDUCATIVA}

Para abordar temas de construcción y deconstrucción de identidad desde la estética, se debe tener presente el contexto social globalizado y dominado por la cultura visual desde los mass media. Este fenómeno lo denomina Acaso (2009, p.213) como una "hiperrealidad" visual en la que los "niños creen firmemente que Harry Potter o incluso Bart Simpson son personajes reales", refiriéndose al error de construir los imaginarios con las narrativas universales. La propuesta didáctica que se presenta aquí se enmarca en la tendencia de introducir micro-narrativas en los contextos educativos, y está formada por tres bloques temáticos que se desglosan a continuación.

\section{Manifestaciones artísticas de las civilizaciones antiguas}

En el primer bloque (Anexo 1, Bloque temático I) se realizó un repaso de las manifestaciones artísticas de las civilizaciones antiguas, revisando materiales, patrones y significados utilizados por las comunidades que poblaron Ecuador (cultura Valdivia, Chorrera, La Tolita, entre otras). Estas son estéticas arraigadas en la cultura ecuatoriana y, por ello, de carácter familiar para los estudiantes.

A nivel práctico, se inició con una dinámica grupal para visibilizar las relaciones de desigualdad histórico-social: se establecieron tres grupos de estudiantes con distintas normas determinadas (uno de ellos es libre de pedir la palabra y opinar, el segundo grupo interviene sentado y admirando la escena, y el tercer grupo solo puede hablar con la mano sobre la boca). La conclusión común es que esas condiciones impuestas han determinado quiénes tenían más visibilidad, y se establecieron jerarquías discriminatorias para los grupos con más obstáculos para la comunicación. Como ejercicio de reflexión, el bloque se dividió en dos debates. El primero se desarrolló en torno al término precolombino, discutiendo si este es un concepto válido para describir el periodo de la historia tradicional latinoamericana, o, más bien, se ha legitimado con este término desde el lenguaje la "gran conquista". Las opiniones finales de los estudiantes indican que este concepto reproduce la "historia única" de los vencedores y que su cuestionamiento abre nuevos planteamientos colectivos (Ver figura 1).

El segundo debate gira en torno a los términos arte, artesanía o folclor. Galeano (2000), desde el ámbito literario, refuerza esta idea irónicamente al hablar de las etnias y civilizaciones antiguas como los "nadie", los olvidados que "no hacen arte, sino 
artesanía. Que no practican cultura, sino folklore” (2000: 59). La producción artística ancestral queda, por lo tanto, relegada y supeditada por las narrativas eurocéntricas como lo "otro" o lo exótico (Albán, 2009, p.88).

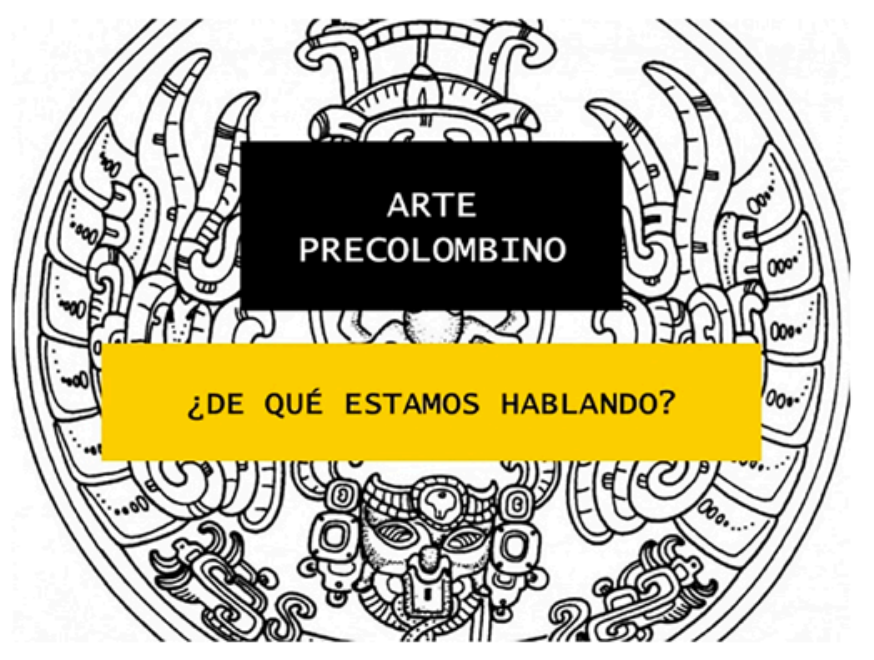

1. Diapositiva de clase. Imagen de la autora.
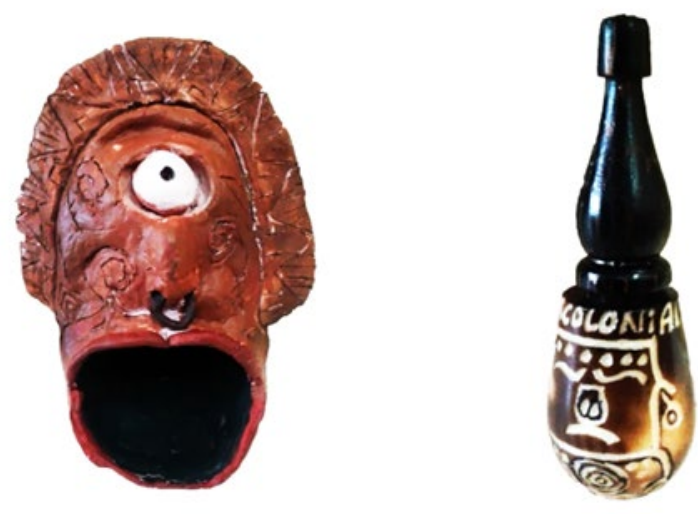

2 y 3. Trabajos de clase desde la estética indígena. Autoras: Jessenia Cedeño y Selena Gutiérrez.

\section{Influencias de las estéticas tradicionales}

Con la llegada de las piezas africanas y latinoamericanas a los países europeos, el arte occidental sufre una serie de modificaciones que dieron lugar a distintos estilos de vanguardia. Sin embargo, no existe el mismo reconocimiento a la hora de legitimar unas u otras producciones artísticas. Este planteamiento lo explica el artista Armando Mariño al considerar que las obras que están fuera de los discursos oficiales se comprenden desde el enfrentamiento a la cultura occidental, y que los referentes artísticos que se inculcan en el proceso de aprendizaje no incluyen discursos alternativos (Sánchez, 2000). El trabajo plástico de este artista es un ejemplo que funciona para el desarrollo del presente bloque temático (Anexo
2, Bloque temático II), ya que desde sus pinturas cuestiona las relaciones del arte vanguardista europeo con las realidades indígenas y, desde una perspectiva crítica, construye imágenes que transmiten esas contradicciones.
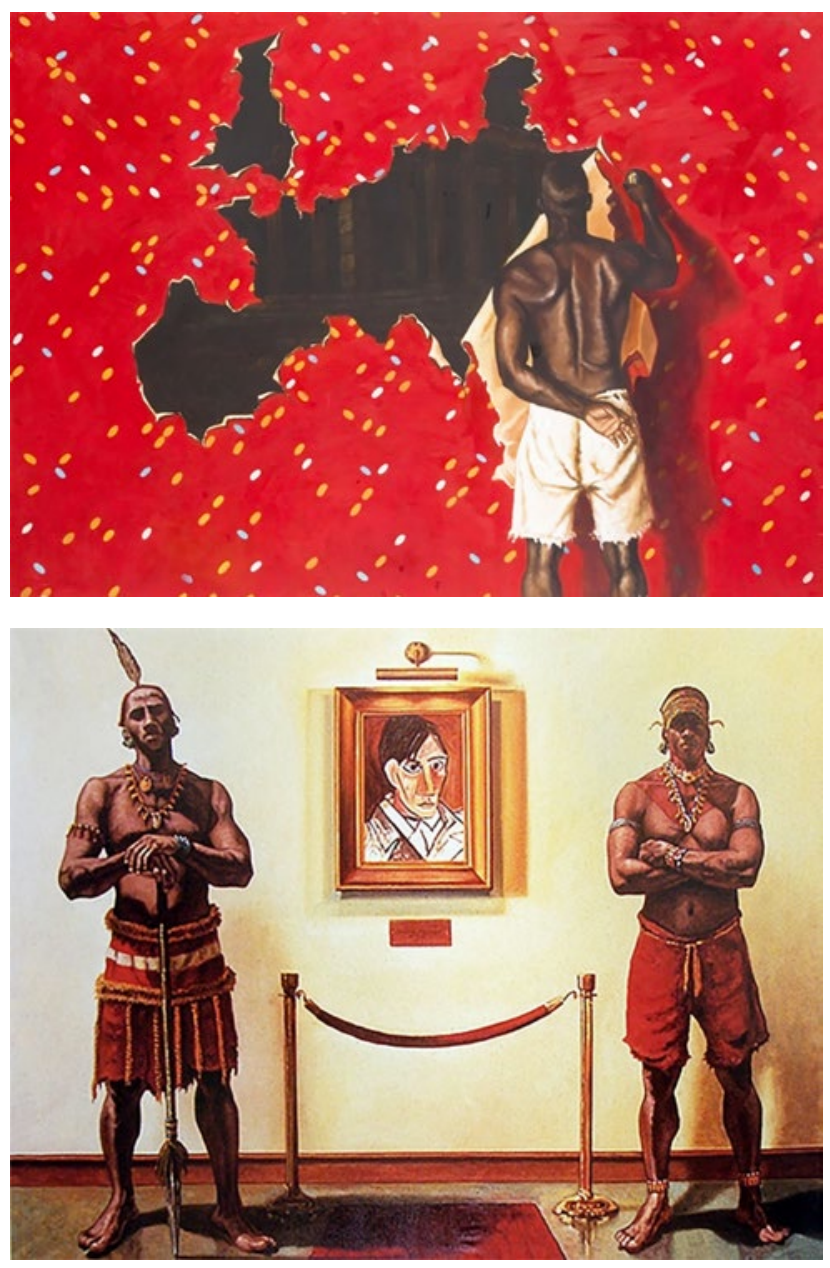

4 y 5. Armando Mariño. Izquierda.: Construyendo la abstracción. Derecha.: Los centinelas. 1998. Recuperado de The Farber Collection.

El objetivo de este bloque didáctico es comprender el recorrido e influencias estéticas que afectan a las obras artísticas de las vanguardias europeas, y se centra en la contraposición de trabajos plásticos entre Armando Mariño y Pablo Picasso. Las actividades prácticas que conforman este apartado son varias revisiones bibliográficas de los textos de Ocampo (2002) y Albán (2013), así como el análisis visual y conceptual de las obras de Armando Mariño.

\section{Referencias estéticas contemporáneas}

El objetivo del último bloque (Anexo 3, Bloque temático III) es conocer los discursos estéticos contemporáneos desde la corriente decolonial para producir trabajos plásticos y/o gráficos de la misma tendencia. Para comenzar, se estudian con los estu- 


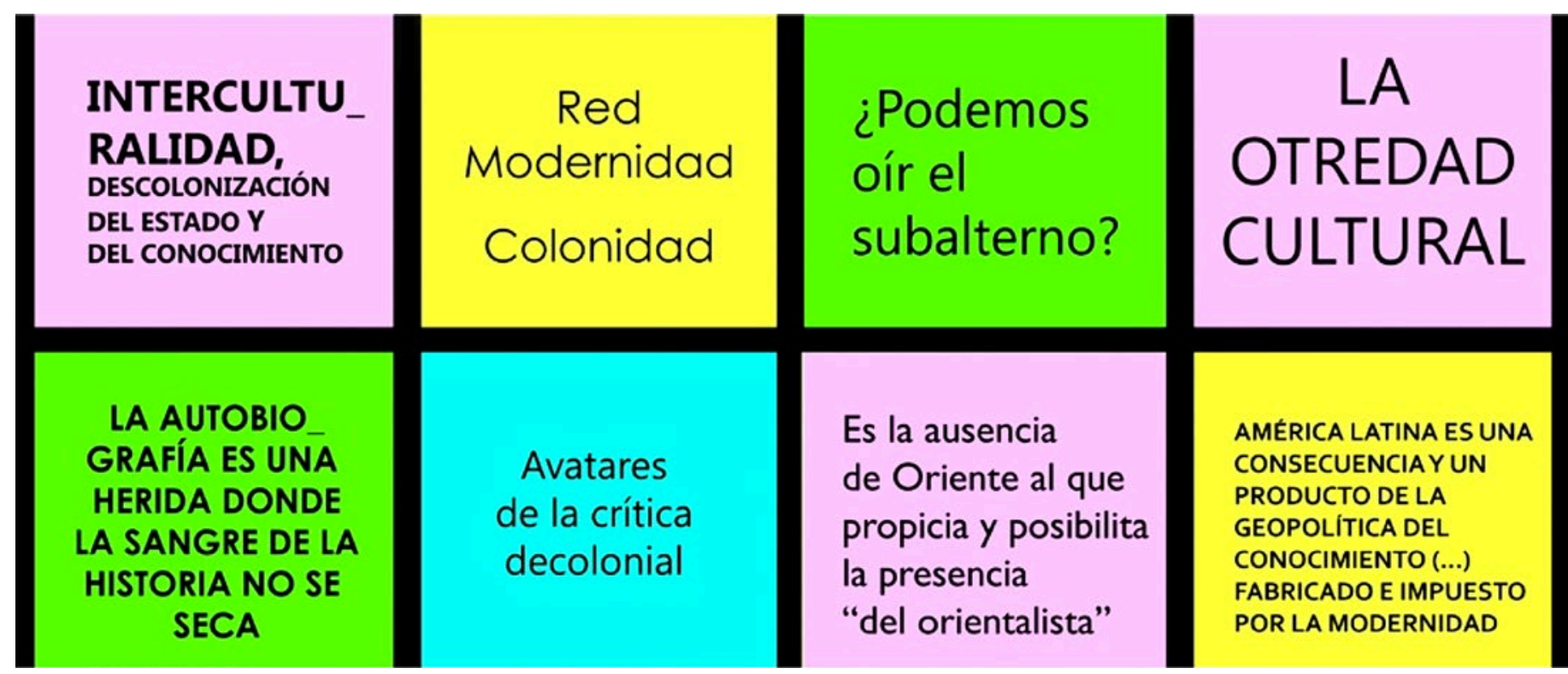

6. Transcripción del ejercicio de citas célebres. Imagen de autora.

diantes algunas citas de autores reconocidos en esta lucha de exaltación de las culturas marginadas, como son Mignolo, Spivak o Castro-Gómez. (Ver figura 6).

Estos fragmentos dan pie a interpretaciones desde otros formatos artísticos. Como primer recurso, se plantean lecturas decoloniales desde las canciones de Calle 13 o Ana Tijoux, en cuyas composiciones expresan de forma crítica la necesidad de exaltación de las identidades latinoamericanas. El primer ejercicio práctico consiste en producir imágenes o ilustraciones extraídas de las letras de esas canciones, llevando el mensaje textual-musical al plano visual.

Otra estrategia para introducir en el aula la estética decolonial fue la contraposición de proyecciones cartográficas (Mercator y Peters) para reflexionar cómo la imagen justifica la realidad cotidiana, traducida en este caso en la construcción de mapas relacionados con las jerarquías de poder. Posteriormente, se revisan algunas producciones gráficas en las que el mapa de América Latina tiene un papel protagonista, como ocurre en la publicación Diseño Latinoamericano. Afiches 2007 (Echevarría, 2007), que consiste en una recopilación de trabajos de cartelería de la Universidad de Palermo desde el diseño gráfico. La justificación de esta estrategia es que:

Cartografía y tejido son apuestas recurrentes en las prácticas artísticas contemporáneas y no es azar que el interés por cartografiar resulte sugerente en un mundo en el que la comunicación y la información en tiempo real, los viajes, la emigración y las fronteras transforman nuestra manera de comprender y habitar el mundo. (Rubiano, 2012, p.59)

El tercer recurso gráfico utilizado fue la representación de figuras históricas y populares de la cultura latinoamericana como símbolo de empoderamiento. En este sentido, se expusieron en el aula distintas imágenes de personajes como el Che Guevara, Frida Kahlo, Silvio Rodríguez, Mercedes Sosa, Diego Armando Maradona... que son iconos de la identidad latinoamericana y que, debido a su prestigio, han sido motivo para la construcción de numerosas manifestaciones visuales: pinturas murales, afiches, objetos de merchandising, etc. El último recurso consiste en un repaso del trabajo de algunos artistas contemporáneos que incluyen en sus obras el discurso decolonial, entre los que destaca, por su acogida en el aula, el trabajo de Nadín Ospina,

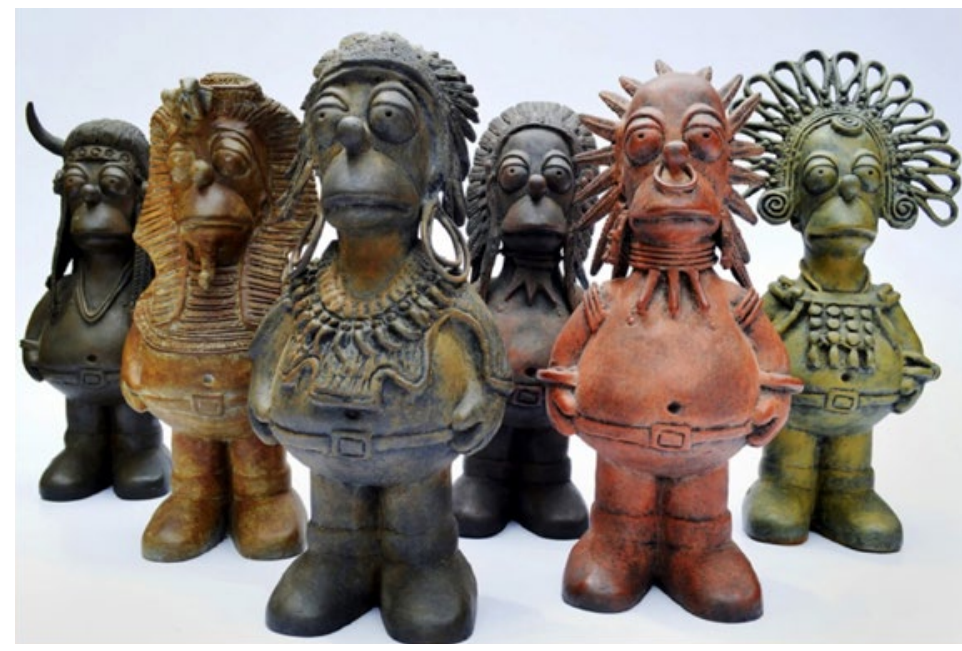

7. Esculturas de Nadín Ospina.

Recuperadas de Art of the Mooc 
quien recupera las formas de las piezas tradicionales para sus objetos de carácter pop, "reterritorializados en formas de representación prehispánicas" como "una alegoría de la globalización cultural". (Rubiano, 2012, p.66).

Los estudiantes, atraídos por este tipo de trabajos, realizaron un ejercicio libre con el que pusieron en marcha su creatividad, y produjeron piezas como las que se presentan en las figuras 8 y 9 .
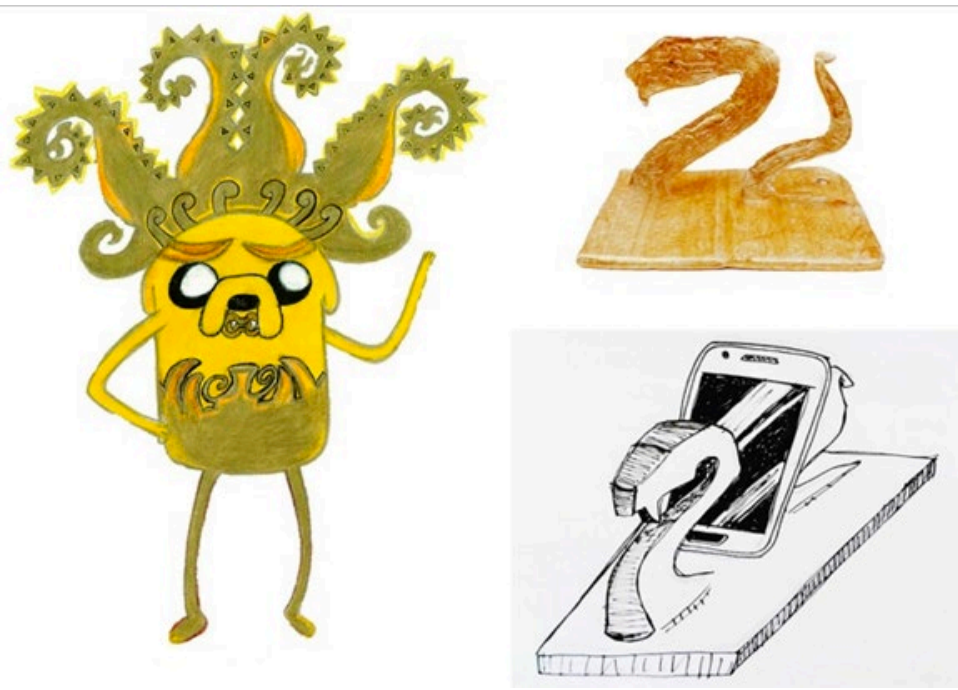

8 y 9. Trabajos de clase desde la estética decolonial contemporánea. Autoras (de derecha. a izquierda.): Génesis Perea y Freida Espantoso.

\section{CONCLUSIONES}

En los procesos académicos oficiales de la provincia de Esmeraldas no se menciona la decolonialidad, aunque los programas didácticos funcionan bajo los parámetros del Plan Nacional del Buen Vivir, que establece las bases de intervención para una sociedad solidaria, dinámica y capaz de contribuir a su propia realidad para mejorar las condiciones del país en todos los niveles. A pesar de ello, la propia cultura y tradición esmeraldeña se mantiene en el diario vivir, ofreciendo espacios y grietas para la inclusión de estos debates y discursos desde ámbitos formales e informales.

En este caso, los estudiantes sí encuentran interesante y necesario llevar los conceptos de la decolonialidad a las aulas del sistema educativo ecuatoriano, e interiorizar de esta manera la importancia de formarse en espacios y tiempos capaces de generar conocimiento crítico y transversal.
La propuesta presentada e implementada tiene, de manera general, una valoración positiva. Los debates se desarrollaron de manera activa, y los estudiantes se sentían identificados con los temas tratados. En cuanto a los referentes visuales compartidos, destaca la aceptación de las obras de Ospina, así como la relación de la teoría decolonial con temas musicales de actualidad. Los materiales que consumen los jóvenes fuera del aula, que se relacionan estrechamente con el medio audiovisual y la estética, sirven para replantear conceptos desde la capacidad creativa individual y grupal. De este modo, las estéticas contemporáneas, el arte, el diseño... funcionan como mediadores culturales entre la "historia única" y la capacidad crítica.

Fomentando desde los diferentes niveles educativos el pensamiento crítico y el conocimiento compartido se construye una sociedad que se entiende como tal, y en la que los futuros profesionales de la imagen puedan continuar equilibrando las posiciones socioculturales de poder. Por ello, evidenciar la relación entre manifestaciones populares desde la cultura y los iconos globales funciona como elemento potenciador en el aula para que los estudiantes sean capaces de generar productos de arte y diseño sobre el discurso de la estética decolonial.

\section{BIBLIOGRAFÍA}

Acaso, M. (2013). rEDUvolution: hacer la revolución en la educación. Madrid: Paidós.

Acaso, M. (2009). La educación artística no son manualidades. Nuevas prácticas en la enseñanza de las artes y la cultura visual. Madrid: Catarata.

Albán, A. (2013). Prácticas culturales basadas en lugar e investigadores locales (ensayo en web). Territorios Sonoro de Colombia. Recuperado de http://www.territoriosonoro. org/marimba/documentacion/investigacion

Albán, A. (2009). Artistas indígenas y afrocolombianas: Entre las memorias y cosmovisiones estéticas de la resistencia. En Mignolo, W. y Palermo, Z. (Comp.) Arte y estética en la encrucijada descolonial (p. 83-112). Buenos Aires: Ediciones del Signo.

Albán, A. (2007). El acto creador como pedagogía emancipatoria y decolonial. En: Seminario de Formación Artística: encuentro con la creatividad, el arte y la educación, Institución educativa de La Pamba, Popayán, Colombia. 
Art of the MOOC. (29 de marzo de 2016). Nadín Ospina (entrada en blog). Recuperado de http://artofthemooc.org/wiki/nadia-ospina/

Campos, S. (2013). Giro “decolonial” y Estética: algunas consideraciones. SalonKritik, abril 21. Recuperado de http://salonkritik. net/10-11/2013/04/giro decolonial y estetica alg.php

De Oto, A. (s.f.). Pensamiento descolonial/decolonial (entrada de blog). En el proyecto: Diccionario del pensamiento alternativo II. Pensamiento Latinoamericano y Alternativo. Recuperado de http://www.cecies.org/articulo. asp?id $=285$

De Sousa Santos, B. (2010). Descolonizar el saber, reinventar el poder. Montevideo: Ediciones Trilce-Extensión universitaria.

Echevarria, O. E. (Dir.) (2007). Diseño latinoamericano. Afiches 2007. Buenos Aires: Universidad de Palermo. Recuperado de http://fido.palermo.edu/servicios dyc/encuentro2008/05 publicaciones/05 libro afiches/2007/LibroAfiches2007.pdf

Escobar, A. (2010). Territorios de diferencia: lugar, movimientos, vida, redes. Envión Editores.

Galeano, E. (2000). El libro de los abrazos. México: Siglo XXI.

Gómez, P. P. y Mignolo, W. (2012). Estéticas decoloniales. Bogotá: Universidad Distrital Francisco José de Caldas.

Gudynas, E. (2013). El malestar moderno con el Buen Vivir: Reacciones y resistencias frente a una alternativa al desarrollo. En: diario La Hora, septiembre 2013. Recuperado de http://lahora.com.ec/index.php/noticias/ show/1101568118/-1/El malestar Moderno con el Buen Vivir: Reacciones y resistencias frente a una \#. V8Xhi 197IW

Jameson, F. (1995). La posmodernidad o la lógica cultural del capitalismo tardio. Barcelona: Paidós.

León, C. (2012). Imagen, medios y telecolonialidad: hacia una crítica decolonial de los estudios visuales. En: Aisthesis, no 51, 109-123. Recuperado de http://www. scielo.cl/scielo.php?script=sci arttext\&pi$\mathrm{d}=$ S0718-71812012000100007

Medrazza, S. (Comp.) (2008). Estudios postcoloniales. Ensayos fundamentales. Madrid: Traficantes de Sueños. Recuperado de http:// www.oozebap.org/biblio/pdf/estudios postcoloniales.pdf
Ocampo, E. (2002). Primitivismo y arte primitivo. Nueva Revista, $\mathrm{n}^{\circ}$ 80, marzo-abril.

Quijano, A. (2012). "Bien vivir": entre el "desarrollo" y la des/colonialidad del poder. En: Viento Sur, $\mathrm{n}^{\circ} 122,46-56$.

Quijano, A. (2002). Colonialidad del poder, globalización y democracia. Trayectorias. Revista de Ciencias Sociales de la Universidad Autónoma Nuevo León, n 7-8, 58-90.

Secretaría Nacional de Planificación y Desarrollo (2013). Plan Nacional para el Buen Vivir 2013-2017 (1 Ed.). Quito: Senplades. Recuperado de http://www.buenvivir.gob. ec/pnbv-popup/-/asset publisher/B9gE/ content/version-plan-nacional-2013-2017

Rogoff, I. (2011). El Giro. Arte y políticas de identidad, vol. 4, junio. Murcia: Servicio de Publicaciones de la Universidad de Murcia.

Rubiano, E. (2012). Discursos curatoriales y prácticas artísticas: aciertos y desencuentros en "Estéticas decoloniales". En Cardona. P. y Solórzano, A. (Comp.) Arte y emancipación estética. Estéticas contemporáneas 3. 55-7. Medellín: Universidad Pontificia Bolivariana.

Sánchez, S. (2000). Advertencias desde el margen. La Habana: Revolución y Cultura, $\mathrm{n}^{\circ}$ 5, 55-57. Recuperado de https://susetsanchez.wordpress.com/entrevistas/armando-marino/

The Farber Collection. (s.f.). Armando Mariño (entrada en blog). Recuperado de http:// www.thefarbercollection.com/es/artists/ armando_marino

Walsh, C. (2008). Interculturalidad, plurinacionalidad y decolonialidad: las insurgencias político-epistémicas de refundar el Estado. Tabula Rasa, n 9, 131-152.

Zizek, S. (1998). Multiculturalismo o la lógica cultural del capitalismo multinacional. En Jameson, F. y Zizek, S. Estudios culturales. Reflexiones sobre el multiculturalismo. 137-188. Buenos Aires: Paidós SAICF. 


\section{ANEXOS: Fichas metodológicas de los bloques temáticos}

Anexo 1. Tabla 1. Estética decolonial en el aula: Ficha del bloque temático I

\section{BLOQUE TEMÁTICO I: Manifestaciones artísticas de las civilizaciones antiguas}

OBJETIVO Reflexionar sobre las producciones de civilizaciones antiguas de América Latina, en concreto de Ecuador, para cuestionar los términos arte, artesanía y folclor, teniendo en cuenta los discursos de poder.

MATERIALES - Ejemplos de piezas y objetos de las civilizaciones antiguas: piezas de museos, de centros culturales, etc.

- Visitas online a catálogos y webs de museos y centros culturales de Ecuador.

-"Pachanga". Diseño gráfico editorial de Belén Mena.

- Textos de Eduardo Galeano.

ACTIVIDADES - Dinámicas grupales-corporales para el cuestionamiento y la reflexión en torno a las posiciones de poder.

- Diseño compositivo a partir de patrones visuales.

- Trabajos plásticos de expresión identitaria a través de la arcilla y la madera.

CONCLUSIÓN El discurso de la "historia única" menosprecia las producciones indígenas o de comunidades latinoamericanas antiguas.

Anexo 2. Tabla 2. Estética decolonial en el aula: Ficha del bloque temático II

\section{BLOQUE TEMÁTICO II: Influencias de las estéticas tradicionales}

OBJETIVO Comprender el recorrido e influencias estéticas tradicionales que afectan y originan las estéticas de vanguardia europeas.

MATERIALES - Trabajo artístico de Pablo Picasso.

- Ejemplos de estética cubista y futurista.

- Trabajo artístico y entrevistas de Armando Mariño.

- Textos de Estela Ocampo.

- Textos de Adolfo Albán Achinte.

ACTIVIDADES - Revisiones bibliográficas y ensayo crítico de los textos.

- Análisis visual y conceptual de las obras de Mariño.

CONCLUSIÓN Las vanguardias que legitima la Historia del Arte tienen una clara influencia de las piezas de civilizaciones antiguas, tanto africanas como americanas. Sin embargo, mientras las primeras representan uno de los periodos más significativos de la Historia del Arte, las segundas se olvidan en ese mismo discurso. 


\section{BLOQUE TEMÁTICO III: Referencias estéticas contemporáneas}

OBJETIVO Conocer los discursos estéticos contemporáneos desde la corriente decolonial para producir trabajos plásticos y/o gráficos propios.

MATERIALES Referencias contemporáneas desde varios ámbitos estético-gráficos:

- Citas célebres de estudiosos de la corriente decolonial.

- Proyección Mercator y Peters (cartografía).

- Grabados de José Guadalupe Posada.

- Trabajo artístico de Guillermo Gómez Peña.

- Trabajo artístico de Nadín Ospina.

- Campaña publicitaria "Fly", de Aviación Tame

ACTIVIDADES - Producción libre de imágenes u objetos de estética y tendencia actual.

CONCLUSIÓN Desde las disciplinas creativas y de la comunicación, como las artes, el diseño y afines, se pueden generar discursos decoloniales a partir de la producción de piezas, imágenes $\mathrm{u}$ otro tipo de trabajos que expresen las reivindicaciones de la corriente decolonial. 